\title{
An animal model of ocular vestibular-evoked myogenic potential in guinea pigs
}

\author{
Ting-Hua Yang $\cdot$ Shing-Hwa Liu • \\ Shou-Jen Wang $\cdot$ Yi-Ho Young
}

Received: 17 August 2009 / Accepted: 21 June 2010

(C) Springer-Verlag 2010

\begin{abstract}
This study aimed to establish an animal model of ocular vestibular-evoked myogenic potential (oVEMP) in guinea pigs. Ten healthy and 10 gentamicin-treated guinea pigs underwent oVEMP test using a hand-held bone-conducted vibrator placed on the animal's forehead. All 10 healthy animals exhibited bilateral oVEMPs at the stimulus intensity of $139 \mathrm{~dB}$ force level (FL), with a mean threshold and latencies of peak $\mathrm{nI}$ and $\mathrm{pI}$ of $130 \pm 4 \mathrm{dBFL}$, $3.17 \pm 0.37 \mathrm{~ms}$ and $4.72 \pm 0.38 \mathrm{~ms}$, respectively. Similar to response rate, the nI-pI amplitude decreased markedly in magnitude as stimulus intensity decreased. Another 10 animals administered with gentamicin $(2 \mathrm{mg})$ on the left ear 1 week after surgery had $100 \%$ clear oVEMPs beneath the left eye (ipsilateral to the lesion side), whereas oVEMPs were absent and reduced beneath the right eye (opposite to the lesion side) in 7 and 3 animals, respectively. Morphological study of animals with absent oVEMPs identified substantial damage to the hair cells of the utricular macula. Quantitative analysis revealed that histological density of intact hair cells of the utricular macula from control and lesion ears were $194 \pm 15$ and $66 \pm 9$ per $130 \times 130 \mu \mathrm{m}^{2}$
\end{abstract}

T.-H. Yang · S.-H. Liu

Institute of Toxicology, College of Medicine,

National Taiwan University, Taipei, Taiwan

T.-H. Yang · Y.-H. Young $(\bowtie)$

Department of Otolaryngology,

National Taiwan University Hospital,

1 Chang-Te St., Taipei, Taiwan

e-mail: youngyh@ntu.edu.tw

\section{S.-J. Wang}

Institute of Biomedical Engineering,

College of Medicine and College of Engineering,

National Taiwan University, Taipei, Taiwan field, respectively, showing a $68 \%$ reduction in the latter. Further, the stereocilia of the residual hair cells were either fused or deformed, and pointed outward randomly. In conclusion, this study establishes the animal model of oVEMP in guinea pigs using bone-conducted vibration stimuli, which sets the stage for investigating the pathophysiology of the utricular disorders.

Keywords Cervical vestibular-evoked myogenic potential - Ocular vestibular-evoked myogenic potential . Utricle $\cdot$ Bone-conducted vibration $\cdot$ Vestibulo-ocular reflex

\section{Introduction}

Vestibular endorgans comprise three semicircular canals and two otolithic organs, i.e. saccule and utricle. Clinically, semicircular canals are assessed by caloric test with videonystagmography or the head impulse test (Halmagyi et al. 2001), whereas the saccule and utricle can be examined using the vestibular-evoked myogenic potential (VEMP) test. Via air-conducted sound (ACS) stimulation, VEMP can be elicited from tonically contracted cervical muscles, the so-called cervical VEMP (cVEMP) (Colebatch et al. 1994), which has been shown to originate from the saccule. Recent investigations revealed that VEMP can also be recorded from extraocular muscles, the so-called ocular VEMP (oVEMP) (Rosengren et al. 2010), which can be elicited by bone-conducted vibration (BCV) on the forehead, and has been referred to the utricular function via a crossed vestibulo-ocular reflex (VOR) (Iwasaki et al. 2007).

Cohen et al. (1964) first studied the eye movements generated by semicircular canal nerve stimulation in experimental animals. Murofushi et al. (1995) demonstrated that 
ACS stimulation is primarily selective for the saccular macula in guinea pigs. Curthoys et al. (2006) proposed that BCV stimuli activate both utricular and saccular afferents in guinea pigs. These experiments set the stage for establishing animal models for inner ear disorders. Previously, we have successfully recorded caloric nystagmus in guinea pigs with experimental perilymph fistula (Young et al. 1992) and cVEMPs in alert guinea pigs (Yang and Young 2005). Applying gentamicin onto the round window membrane of guinea pigs proved that absent cVEMPs are strongly correlated with the toxic effect of gentamicin on the saccule (Day et al. 2007), mostly type I hair cells (Lue et al. 2009). As the pathophysiology of the saccular disorder has been thoroughly examined, this study aimed to establish an animal model of oVEMP in guinea pigs to investigate the pathophysiology of utricular lesions.

\section{Materials and methods}

\section{Animal preparation}

Ten Hartley-strain guinea pigs weighing 200-220 g were used in a preliminary study. Each animal was kept alert and underwent oVEMP test without anesthesia or operation.

Another 10 guinea pigs weighing 200-220 g treated with gentamicin were also used in this study. Under intraperitoneal pentobarbital sodium $(35 \mathrm{mg} / \mathrm{kg})$ anesthesia, the tympanic bulla was opened via post-auricular incision to expose the round window membrane under operating microscope (Young et al. 1992). Using a microsyringe, an amount of $0.05 \mathrm{ml}$ of gentamicin $(40 \mathrm{mg} / \mathrm{ml})$ was dropped directly on the round window membrane of the left ear. To exclude the effect of operation, another $0.05 \mathrm{ml}$ of saline was also dropped onto the right round window membrane and served as the control. Then, the incision wounds were sutured and the animal was kept on the recumbent position with the lesion (left) ear up to ensure the gentamicin contact with the round window membrane until the animal awoke, approximately $6 \mathrm{~h}$ after operation. Thereafter, animals were housed at $23 \pm 2{ }^{\circ} \mathrm{C}$ and $55 \pm 5 \%$ humidity and fed a solid diet and tap water ad libitum. One week after surgery, each animal underwent oVEMP test and then was killed for morphological study.

\section{oVEMP test}

Each animal was restrained by a special clamp (Fig. 1), with its head and body fixed, but four legs left free in a prone position (Young et al. 1991). Five subdermal needleelectrodes (ES43-838, Technomed Europe, The Netherlands) were employed. On each side, one active electrode was inserted vertically on the skin $5 \mathrm{~mm}$ above the inferior

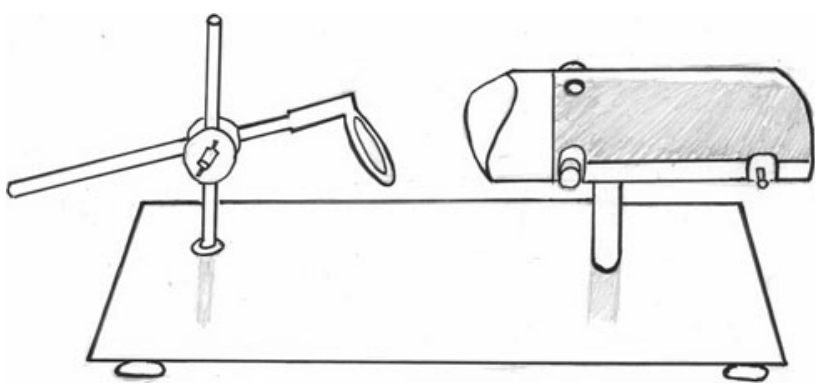

Fig. 1 Illustration of the special clamp for small animals. The collar is used for fixating the animal's head and the column is for fixating the animal's body

orbital rim in or close to the inferior extraocular muscle without penetrating the eye ball. Another electrode (reference) was inserted approximately $15 \mathrm{~mm}$ below the respective active electrode. The ground electrode was placed on the parietal area at the midline. All electrodes were carefully inserted with a depth of 5-10 $\mathrm{mm}$ from the skin. Since the subdermal needle-electrode was very fine $(0.4 \mathrm{~mm}$ in diameter), the animal tolerated it very well without bleeding or blinking. If the animal suffered from pain or discomfort, struggling of the animal would definitely contaminate the oVEMP waveform, leading to failure of the experiment. Fortunately, such condition was not observed and each animal stayed quiet and calm without untoward effect.

Single square wave stimuli of $0.6 \mathrm{~ms}$ in duration were transmitted to a hand-held vibrator with $1.81 \mathrm{~kg}$ in weight, $9.6 \mathrm{~cm}$ in height and $7.8 \mathrm{~cm}$ in diameter (V201 vibrator, Ling Dynamic Systems, Royston, England) for head vibration, which was driven by a custom amplifier. Drive voltage was adjusted and fixed to produce a peak force level (FL) of $139 \mathrm{~dB}($ re $1 \mu \mathrm{N})$ from the vibrator, as measured by an artificial mastoid (model 4930, Bruel \& Kjaer P/L, Denmark). The operator held the vibrator by hand and supported most of its weight such that the pole tip delivered a repeatable tap on the midline frontal bone of a guinea pig (Fig. 2). During recording (Smart EP 3.90, Intelligent Hearing Systems, Miami, FL, USA), electromyographic (EMG) signals were amplified and bandpass filtered to $1-1,000 \mathrm{~Hz}$. Stimulation rate was $5 \mathrm{~Hz}$; analysis time for each response was $24 \mathrm{~ms}$; and 30 responses were averaged for each run. Since the artifact signal from eye blinks or voluntary eye movement is larger in amplitude than a normal evoked potential, the recorded potential exceeding a preset threshold $(90 \mu \mathrm{V})$ was recognized as an artifact and thus rejected during data acquisition. This automatic online rejection system was utilized to eliminate the disturbance of artifact.

Each animal underwent a serial oVEMP testing, with the peak stimulus intensity from 139dBFL initially, followed by 5 -dBFL step decrement, until the absence of the waveforms. The stimulus intensity was then increased in steps of 
Fig. 2 Illustration of the oVEMP test in a guinea pig. On each side, one active electrode is inserted in or close to the inferior extraocular muscle and another reference electrode is about $1.5 \mathrm{~cm}$ below the respective active one.

The ground electrode is placed on the parietal area at the midline. The operator holds the vibrator by hand and supports most of the weight so that the pole tip delivers a repeatable tap on the forehead of a guinea pig

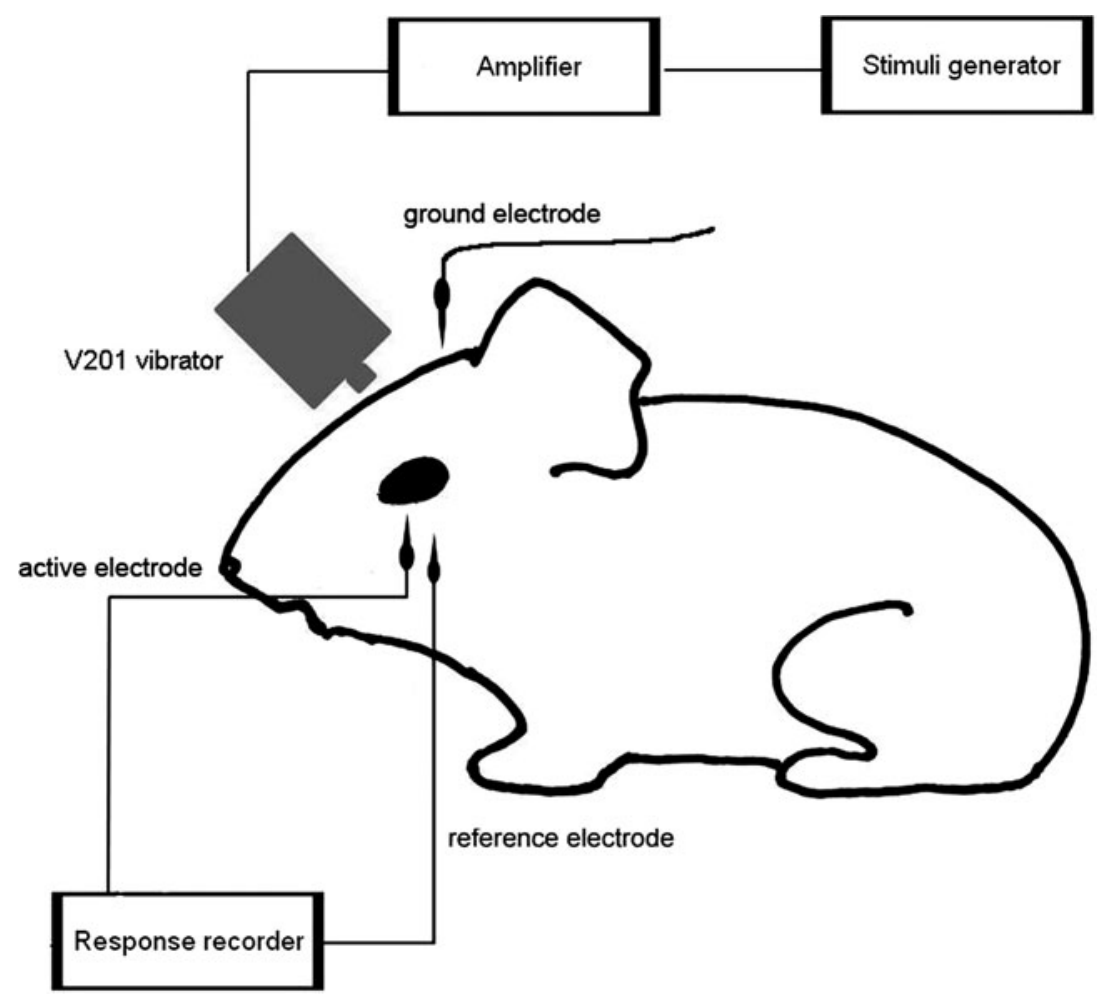

5 dBFL until the oVEMP response reappeared, and the threshold was thus determined.

The initial negative-positive biphasic waveform comprised peaks $\mathrm{nI}$ and $\mathrm{pI}$. Consecutive runs were performed to confirm the reproducibility of peaks $\mathrm{nI}$ and $\mathrm{pI}$, which were interpreted by two independent observers, and oVEMPs were deemed to be present. Conversely, oVEMPs were deemed to be absent when the biphasic waveform was not reproducible. Thereafter, the latencies of peak $\mathrm{nI}$ and $\mathrm{pI}$, amplitude nI-pI, and asymmetry ratio (\%) were measured. The latter was defined as the difference of the amplitude $\mathrm{nI}-\mathrm{pI}$ on each ear divided by the sum of amplitude nI-pI of both ears, that is, (larger amplitude - smaller amplitude/larger amplitude + smaller amplitude) $\times 100$.

\section{Morphological study}

After deep anesthesia with pentobarbital $(50 \mathrm{mg} / \mathrm{kg})$ administered intraperitoneally, all guinea pigs were decapitated. The utricles were then dissected immediately from temporal bones, fixed in $4 \%$ paraformaldehyde and $1 \%$ glutaraldehyde in phosphate-buffered saline (PBS) for $20 \mathrm{~min}$ at $20^{\circ} \mathrm{C}$, and then permeabilized with $5 \%$ Triton $\mathrm{X}-100$ in PBS for $30 \mathrm{~min}$. Non-specific binding was blocked by $10 \%$ fetal bovine serum. The utricular preparations were subsequently stained with rhodamine phalloidin (1:100, SigmaAldrich, St. Louis, MO, USA) in PBS for $1 \mathrm{~h}$. Phalloidin specifically binds to F-actin, which is abundant in the stereocilia and cuticular plate of the hair cells. When the fluorescent dye rhodamine conjugated with phalloidin, it labels F-actin and emits red fluorescence. After staining, explants were washed three times with PBS and mounted onto glass slides with Fluoromount (Molecular Probes, USA). Finally, slides were examined via confocal microscopy (Zeiss LSM 510 Meta, Germany). The excitation wavelength was $561 \mathrm{~nm}$ and the emission wavelength was long-pass filtered over $575 \mathrm{~nm}$.

Quantitative analysis of the hair cells in the utricular sensory epithelia was performed on confocal micrographs. Each micrograph covered an area of $130 \times 130 \mu \mathrm{m}^{2}$. Five random micrographs from one utricle were selected. The number of hair cells in each micrograph was counted by two independent observers and then averaged.

Statistical methods

The response rates among various stimulus intensities were compared by Cochran's Q test. The relationships between the stimulus intensity and the latencies or amplitude were analyzed by one-way analysis of variance test. The response rates between lesion and control sides were compared by Fisher's exact test. The latencies between lesion and control sides were compared by Student's $t$ test. The histological densities of the hair cells between both sides were compared by Mann-Whitney test. A significant difference indicates $P<0.05$.

This study was institutional review board approved, was conducted in accordance with the guideline for the care and 
use of laboratory animals by the Animal Research Committee in National Taiwan University, College of Medicine.

\section{Results}

oVEMPs in healthy guinea pigs

Figure 3 illustrates the biphasic nI-pI waveform of oVEMPs in an alert guinea pig under various BCV stimuli. The response rates of oVEMP in 10 healthy guinea pigs (20 eyes) at stimulus intensities of 139, 134, 129, and 124 dBFL were $100,90,75$, and $15 \%$, respectively, demonstrating that response rates decreased significantly as stimulus intensity decreased $(P<0.05$, Cochran's $Q$ test $)$. The mean threshold of oVEMP in these animals was $130 \pm 4$ (mean $\pm \mathrm{SD}$ ) dBFL.

The mean latencies of the peak $\mathrm{nI}$ for $\mathrm{BCV}$ stimulation of 139,134 , and $129 \mathrm{dBFL}$ were $3.17 \pm 0.37,3.23 \pm 0.43$, and $3.37 \pm 0.41 \mathrm{~ms}$, respectively; the differences among them were non-significant $(P>0.05$, one-way analysis of variance test, Table 1). Likewise, the mean latencies of the peak pI under BCV of 139, 134, and $129 \mathrm{dBFL}$ did not differ significantly $(P>0.05$, one-way analysis of variance test, Table 1).

The mean amplitudes nI-pI stimulated by BCV of 139 , 134 , and $129 \mathrm{dBFL}$ were $64.2 \pm 39.8,45.2 \pm 26.0$, and $31.2 \pm 16.5 \mu \mathrm{V}$, respectively. Similar to the response rate, the amplitude nI-pI decreased significantly in magnitude as stimulus intensity decreased $(P<0.05$, one-way analysis of
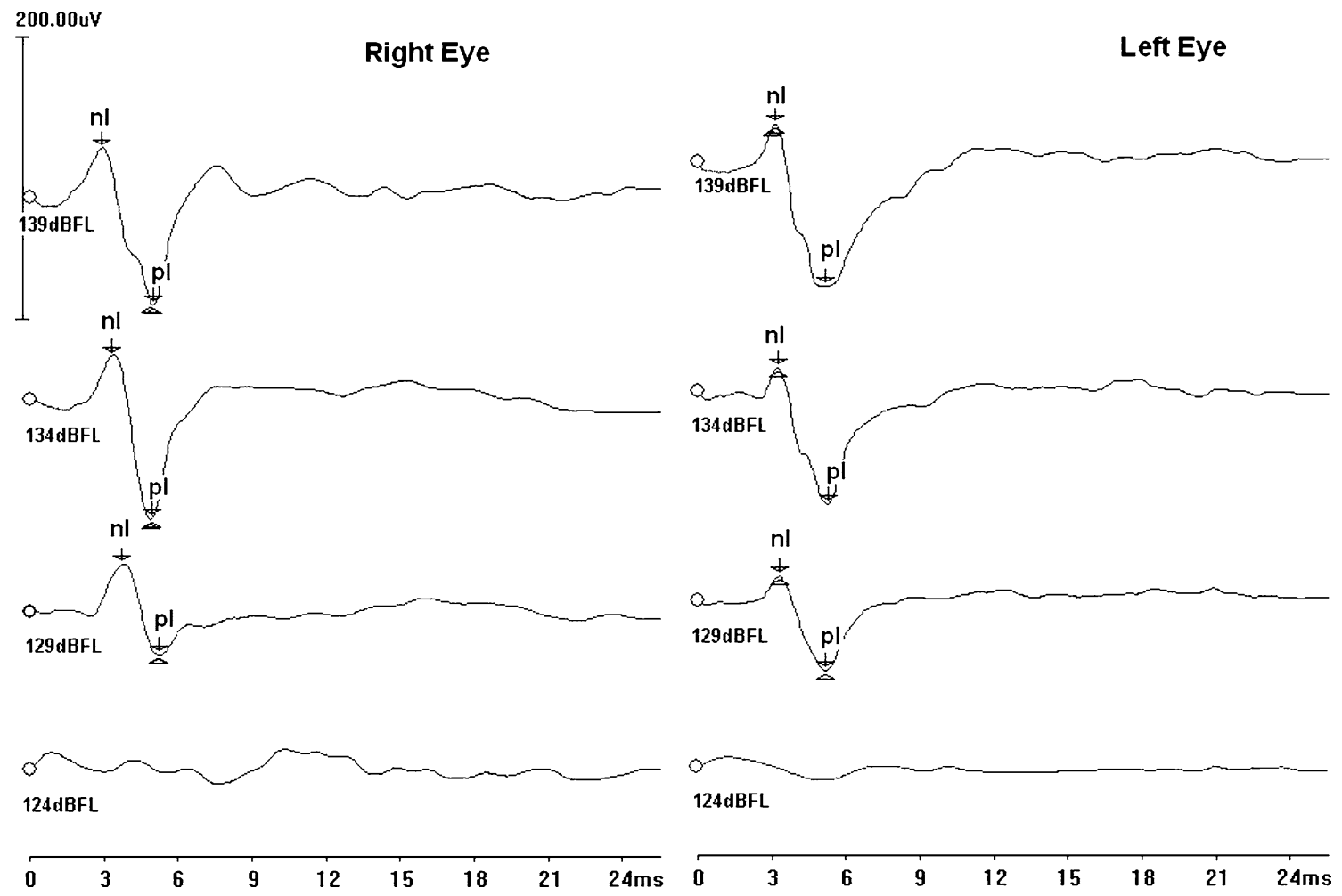

Fig. 3 Typical biphasic nI-pI waveform of oVEMPs in a guinea pig under various bone-conducted vibration stimuli ( $F L$ force level)

Table 1 Comparison of the latencies and amplitudes of ocular vestibular-evoked myogenic potentials in guinea pigs among different stimulus intensities

\begin{tabular}{llllll}
\hline Stimulus intensity & $N$ (eyes) & Response rate & nI Latency $(\mathrm{ms})$ & pI Latency $(\mathrm{ms})$ & nI-pI Amplitude $(\mu \mathrm{V})$ \\
\hline $139 \mathrm{dBFL}$ & 20 & $100 \%$ & $3.17 \pm 0.37$ & $4.72 \pm 0.38$ & $64.2 \pm 39.8$ \\
$134 \mathrm{dBFL}$ & 20 & $90 \%$ & $3.23 \pm 0.43$ & $5.17 \pm 0.77$ & $45.2 \pm 26.0$ \\
$129 \mathrm{dBFL}$ & 20 & $75 \%$ & $3.37 \pm 0.41$ & $4.92 \pm 0.43$ & $31.2 \pm 16.5$ \\
$P$ value & & $0.022^{*}$ & $0.476^{\#}$ & $0.167^{\#}$ & $0.047^{\#}$ \\
\hline
\end{tabular}

Data are expressed as mean $\pm \mathrm{SD}$

$F L$ force level, * Cochran's Q test, ${ }^{*}$ One-way analysis of variance test 
variance test, Table 1). The mean asymmetry ratio stimulated by BCV of $139 \mathrm{dBFL}$ is $18 \pm 8 \%$. Those with asymmetry ratio $>34 \%$ were defined as reduced response.

oVEMPs in guinea pigs under general anesthesia

Exactly how general anesthesia affects oVEMPs was evaluated by administering healthy guinea pigs pentobarbital (35 mg/kg) intraperitoneally. No animals displayed the typical biphasic nI-pI waveform, bilaterally.

oVEMPs in gentamicin-treated guinea pigs

Another 10 animals administered saline (right ear) and gentamicin (left ear) 1 week after surgery underwent oVEMP test via $\mathrm{BCV}$ stimuli. Clear oVEMPs were recorded beneath the left eye (ipsilateral to the lesion side) in all 10 animals, whereas 7 animals had absent oVEMPs (Fig. 4) and 3 animals had reduced oVEMPs beneath the right eye (opposite to the lesion side). No significant difference existed between the two sides in terms of latencies $\mathrm{nI}$ and $\mathrm{pI}$ $(P>0.05$, Student's $t$ test, Table 2$)$; however, the response rate differed significantly between the two sides $(P<0.01$, Fisher's exact test, Table 2). Mean asymmetry ratio of amplitude in these 10 animals was $80 \pm 31 \%$.

Morphological study of the utricle

In the control ears, via confocal images of whole mount preparations of the utricle, the hair cells stained with rhodamine phalloidin were red, and nuclei were blue when counterstained with 4'-6-diamidino-2-phenylindole (DAPI). The utricle retained its normal architecture with the nuclei of hair cells lined up with regular gaps. Hair cells were in order with well-recognized stereocilia on top pointing in a uniform direction (Fig. 5a).

In the lesion ears, hair cells scattered in the utricular preparation. The remaining hair cells were in disarray and

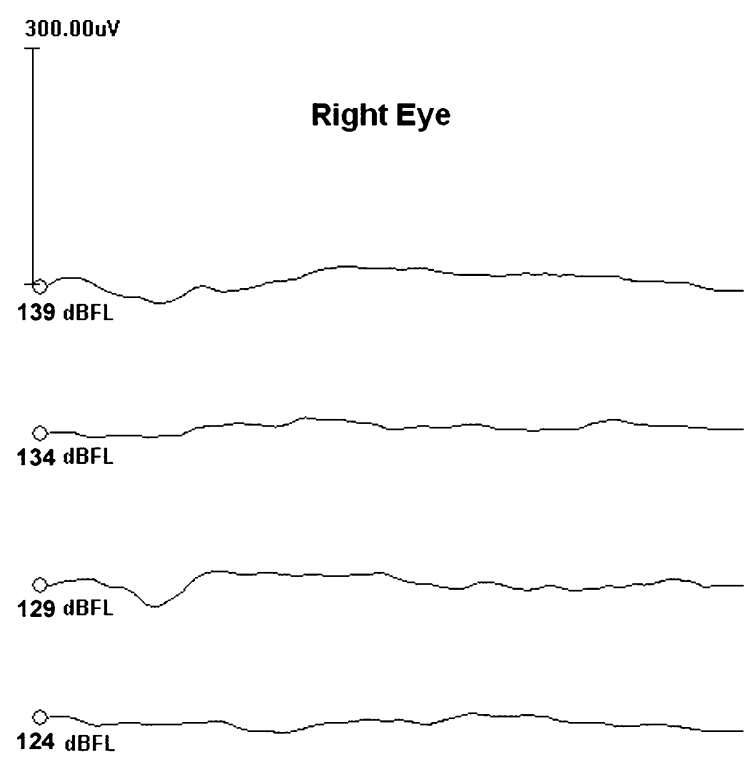

\section{Left Eye}
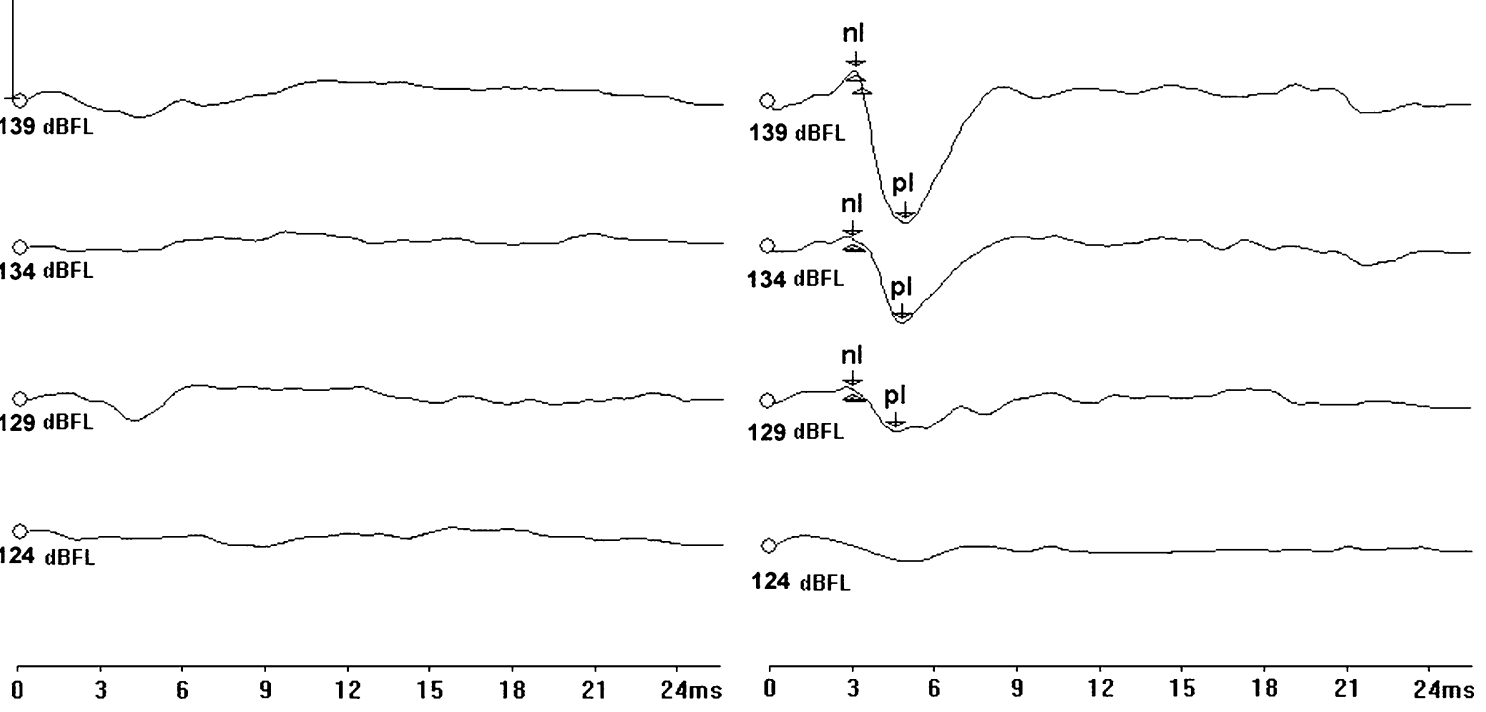

Fig. 4 Guinea pig treated with saline (right) and gentamicin (left), 1 week after operation. Clear oVEMPs with the threshold of 129 dBFL are elicited beneath the left eye (lesion side) but not beneath the right eye (control side). $F L$ force level

Table 2 Ocular vestibular-evoked myogenic potentials in gentamicin-treated guinea pigs, left, 1 week after treatment

\begin{tabular}{llllll}
\hline & $N$ (eyes) & Response rate & nI Latency $(\mathrm{ms})$ & pI Latency $(\mathrm{ms})$ & Asymmetry ratio $(\%)$ \\
\hline Right eye & 10 & $30 \%$ & $3.15 \pm 0.23$ & $4.37 \pm 0.58$ & $80 \pm 31$ \\
Left eye & 10 & $100 \%$ & $3.06 \pm 0.29$ & $4.56 \pm 0.66$ & \\
$P$ value & & $0.003^{*}$ & $0.885^{\#}$ & $0.735^{\#}$ & \\
\hline
\end{tabular}

Due to crossed responses, measuring from the right eye is the lesion side. Data are expressed as mean \pm SD

* Fisher's exact test, ${ }^{\#}$ Student's $t$ test 
Fig. 5 Confocal images of the utricular surface of a gentamicin-treated guinea pig, 1 week after surgery. The stereocilia and cuticular plate in hair cells are red, and nuclei are blue. a Control ear. b Lesion ear. Loss of hair cells is noted, with the remaining hair cells scattered in disarray. The stereocilia are either fused or deformed, pointing outward in random directions
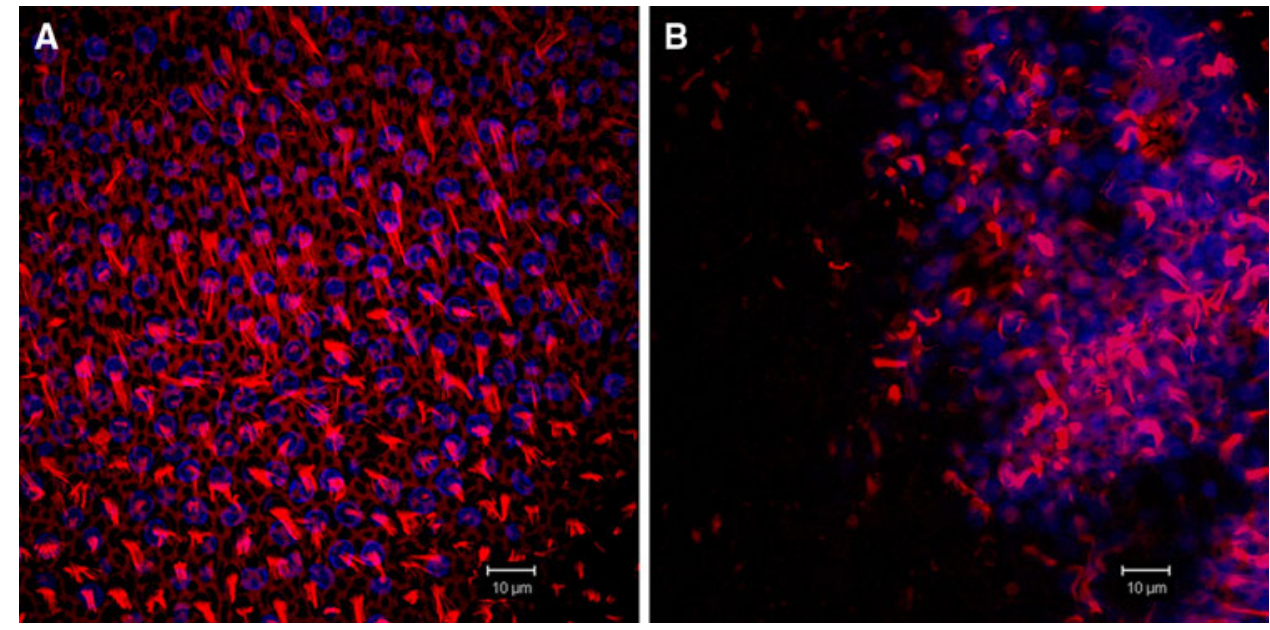

lost their alignments, reflecting the toxic effect of gentamicin. The stereocilia of the residual hair cells were either fused or deformed, and pointed outward randomly (Fig. 5b).

Further quantitative analysis revealed that histological density of intact hair cells of the utricular macula from control and gentamicin-treated ears were $194 \pm 15$ and $66 \pm 9$ per $130 \times 130 \mu \mathrm{m}^{2}$ field, respectively, showing a $68 \%$ reduction in the latter, with a significant difference between the two groups $(P<0.05$, Mann-Whitney test).

For other vestibular endorgans, the hair cells in the crista ampullaris and saccule were also damaged to the extent similar to the utricle. The detail has been reported elsewhere (Day et al. 2007; Lue et al. 2009).

\section{Discussion}

In daily life, rotational movement is sensed by the three semicircular canals, whereas linear motion is perceived by the utricle and saccule. The utricle lies along the interaural axes and detects horizontal translation, whereas the saccule is oriented along the vertical axes and evaluates vertical translation (Fernandez et al. 1972). To understand the physiological characteristics of these otolithic organs, a thorough knowledge of otolithic morphology is required.

Morphological polarization of the receptor polarization in the utricular macula is from the periphery toward the striola, whereas an opposite polarization exists in the saccular macula. Unlike the saccular macula, which is closely attached to the bony surface of the temporal bone, the utricular macula is attached to the temporal bone only at the anterior region of the macula (Uzun-Coruhlu et al. 2007). Quantitatively, the absolute number of afferent fibers arising from the utricle exceeds that arising from the saccule (Rosenhall 1972). Further, the superior division of the vestibular nerve innervates the lateral and superior ampullae, the utricle and a small "hook" portion of the saccular macula. The inferior division of the vestibular nerve supplies the elongated portion of the saccular macula and the posterior ampulla (de Burlet 1924). Among these afferents, the lateral ampullary nerve and utricular nerve are connected, as are the inferior vestibular nerve and cochlear nerve (Bergstrom 1973).

Because the biomechanical properties of the two otolithic organs differ, various electrophysiological tests for each are required. ACS stimuli delivered to the guinea pigs elicits cVEMPs (Yang and Young 2005), as the irregular saccular neurons that likely originate predominantly from the striolar of the saccular macula are preferentially activated by ACS stimulation and are sensitive to change in linear acceleration (Didier and Cazals 1989; Murofushi et al. 1995; Goldberg 2000). In contrast, irregular afferents from the otolithic macula were selectively stimulated at low stimulus intensities by BCV stimuli (Curthoys et al. 2006). In other words, the saccule can be stimulated by both ACS and BCV modes in guinea pigs; while the utricular macula is more selectively stimulated by BCV mode. Based on these findings, we established a novel animal model of oVEMPs.

Conventional instruments for evoked potentials are typically equipped with a maximum level of $70 \mathrm{dBnHL}(107$ $\mathrm{dBFL}$ ) for bone-conducted sound. However, this stimulation intensity is lower than the normal threshold for eliciting oVEMPs in humans (130 $\pm 1 \mathrm{dBFL}$ ) (Welgampola et al. 2008) or guinea pigs ( $130 \pm 4 \mathrm{dBFL})$. Since oVEMPs in response to repeat stimuli from a vibrator are reliable and head taps can activate a crossed VOR in humans (Iwasaki et al. 2007), a powerful vibrator was utilized to trigger oVEMPs in guinea pigs. Thus, a hand-held vibrator was attached to the frontal bone of a guinea pig to deliver a repeatable tap (Fig. 2), and the oVEMPs were recorded from or close to the extraocular muscles (Fig. 3), with a mean latency of $\mathrm{nI}$ around $3 \mathrm{~ms}$ (Table 1). 
The BCV can produce compression and shear waves that travel through the skull and produce head accelerations that are simultaneous and generally of equal amplitude in both ears. The effect is sufficient to stimulate the most sensitive otolithic receptor cells. With elevated absolute acceleration magnitudes caused by $\mathrm{BCV}$, the response rate and amplitude nI-pI were increased in guinea pigs (Table 1), consistent with the literature that most irregular otolithic afferents showed a significant increase in firing rate in response to BCV stimuli (Curthoys et al. 2006).

In our previous report using the same model of gentamicin-treated guinea pigs, auditory brainstem response (ABR) displayed normal responses in $70 \%$ and elevated threshold in $30 \%$ of the animals (Day et al. 2007). Since BCV also stimulates the cochlea, are the recorded oVEMPs contaminated by ABR? Thus, animals were treated with pentobarbital intraperitoneally, since VOR rather than ABR can be influenced by the anesthesia. An absence of oVEMP under general anesthesia indicates that oVEMPs are rather myogenic than neurogenic. In addition, lack of very short latency potentials (Mason et al. 1996) implies no cochlear contribution on the waveform of oVEMPs. Moreover, to support the theory that oVEMPs are related to a crossed VOR, guinea pigs were administered with saline on the right ear and gentamicin on the left ear. Consequently, the oVEMPs were identified beneath the eye on the left (lesion) side, whereas absent or reduced oVEMPs were noted on the right (control) side (Fig. 4), further confirming a crossed VOR.

One may argue why reduced oVEMPs beneath the eye on the control side still existed in $30 \%$ of the animals, resulting in the asymmetry ratio of amplitude as $80 \pm 31 \%$ not $100 \%$ (Table 2). The reason may be that some residual cells $(32 \%)$ still exist in the utricular maculae or that otolithic-ocular pathway may not be completely crossed (Iwasaki et al. 2009).

Morphologically, substantial damage to the hair cells of the utricle and their stereocilia was observed in lesion ears (Fig. 5). Although some residual hair cells existed, their stereocilia were either fused or deformed, which may explain why absent oVEMPs ensued. Nevertheless, absent oVEMPs may also be due to the saccule damaged by gentamicin, because very few canal neurons could be activated at the maximum levels of BCV stimuli (Curthoys et al. 2006). Recently, Curthoys (2010) proposed that the oVEMP to BCV stimuli occurs not because it is only utricular afferents which are activated by BCV but because the eye movement response is predominantly determined by utricular activation. Thus, further study in saccule- or utricle-ablated animals undergoing oVEMP test may help to elucidate the origin of oVEMPs by BCV stimuli.

\section{Conclusion}

This study establishes the animal model of oVEMP in guinea pigs using BCV stimulation, which sets the stage for investigating the pathophysiology of the utricular disorders.

\section{References}

Bergstrom B (1973) Morphology of the vestibular nerve. II. The number of myelinated vestibular nerve fibers in man at various ages. Acta Otolaryngol 76:173-179

Cohen B, Suzuki JI, Bender MB (1964) Eye movements from semicircular canal nerve stimulation in the cat. Ann Otol Rhinol Laryngol 73:153-169

Colebatch JG, Halmagyi GM, Skuse NF (1994) Myogenic potentials generated by a click-evoked vestibulocollic reflex. J Neurol Neurosurg Psychiatry 57:190-197

Curthoys IS (2010) A critical review of the neurophysiological evidence underlying clinical vestibular testing using sound, vibration and galvanic stimuli. Clin Neurophysiol 121:132-144

Curthoys IS, Kim J, McPhedran SK, Camp AJ (2006) Bone-conducted vibration selectively activates irregular primary otolithic vestibular neurons in the guinea pig. Exp Brain Res 175:256-267

Day AS, Lue JH, Yang TH, Young YH (2007) Effect of intratympanic application of aminoglycosides on click-evoked myogenic potentials in guinea pigs. Ear Hear 28:18-25

De Burlet HM (1924) Zur Innervation der Macula sacculi bei Saugetieren. Anat Anzig 58:26-32

Didier A, Cazals Y (1989) Acoustic responses recorded from the saccular bundle on the eighth nerve of the guinea pigs. Hear Res $37: 123-128$

Fernandez C, Goldberg JM, Abend WK (1972) Response to static tilts of peripheral neurons innervating otolith organs of the squirrel monkey. J Neurophysiol 35:978-987

Goldberg JM (2000) Afferent diversity and the organization of central vestibular pathways. Exp Brain Res 130:277-297

Halmagyi GH, Aw ST, Cremer PD, Curthoys IS, Todd MJ (2001) Impulsive testing of individual semicircular canal function. Ann NY Acad Sci 942:192-200

Iwasaki S, McGarvie LA, Halmagyi GM, Burgess AM, Kim J, Colebatch JG, Curthoys IS (2007) Head taps evoke a crossed vestibulo-ocular reflex. Neurology 68:1227-1229

Iwasaki S, Chihara Y, Smulders YE, Burgess AM, Halmagyi GM, Curthoys IS, Murofushi T (2009) The role of the superior vestibular nerve in generating Ocular vestibular-evoked myogenic potentials to bone-conducted vibration at Fz. Clin Neurophysiol 20:588-593

Lue JH, Day AS, Cheng PW, Young YH (2009) Vestibular evoked myogenic potentials are heavily dependent on type I hair cell activity of the saccular macula in guinea pigs. Audiol Neurotol 14:59-66

Mason S, Garnham C, Hudson B (1996) Electric response audiometry in young children before cochlear implantation: a short latency component. Ear Hear 17:537-543

Murofushi T, Curthoys IS, Topple AN, Colebatch JG, Halmagyi GM (1995) Responses of guinea pig primary vestibular neurons to clicks. Exp Brain Res 103:174-178

Rosengren SM, Welgampola MS, Colebatch JG (2010) Vestibular evoked myogenic potentials: past, present and future. Clin Neurophysiol 121:636-651

Rosenhall U (1972) Vestibular macular mapping in man. Ann Otol $81: 339-351$ 
Uzun-Coruhlu H, Curthoys IS, Jones AS (2007) Attachment of the utricular and saccular maculae to the temporal bone. Hear Res 233:77-85

Welgampola MS, Myrie OA, Minor LB, Carey JP (2008) Vestibularevoked myogenic potential thresholds normalize on plugging superior canal dehiscence. Neurology 70:464-472

Yang TH, Young YH (2005) Click-evoked myogenic potentials recorded on alert guinea pigs. Hear Res 205:277-283
Young YH, Nomura Y, Okuno T, Hara M (1991) Clip electrode method for recording eye movements in experimental animals. Eur Arch Otorhinolaryngol 248:331-334

Young YH, Nomura Y, Hara M (1992) Vestibular pathophysiologic change in experimental perilymphatic fistula. Ann Otol Rhinol Laryngol 101:612-616 